\title{
Fibroblast growth factor 8 is expressed at higher levels in lactating human breast and in breast cancer
}

\section{Zammit', R Coope', JJ Gomm', S Shousha', CL Johnston' and RC Coombes*,'}

'Cancer Research (UK) Laboratories, Department of Cancer Medicine, Imperial College, Hammersmith Hospital, Du Cane Road, London WI2 ONN, UK

\begin{abstract}
Fibroblast growth factor 8 can transform $\mathrm{NIH} 3 \mathrm{~T} 3$ cells and its expression has been found to be associated with breast and prostate cancer. Following our finding that fibroblast growth factor 8 mRNA expression is increased in breast cancer, we have undertaken an immunohistochemistry study of fibroblast growth factor 8 expression in a series of human breast tissues and other normal tissues. Our findings confirm increased expression of fibroblast growth factor 8 in malignant breast tissue but also show significant fibroblast growth factor 8 expression in non-malignant breast epithelial cells. No significant difference in fibroblast growth factor 8 expression was found between different grades of ductal carcinoma, lobular carcinoma and ductal carcinoma in-situ or cancer of different oestrogen receptor, progesterone receptor or nodal status. The highest levels of fibroblast growth factor 8 expression were found in lactating breast tissues and fibroblast growth factor 8 was also detected in human milk. A survey of other normal tissues showed that fibroblast growth factor 8 is expressed in the proliferative cells of the dermis and epithelial cells in colon, ovary fallopian tube and uterus. Fibroblast growth factor 8 appears to be expressed in several organs in man and appears to have an importance in lactation.

British Journal of Cancer (2002) 86, 1097 - I 103. DOI: I0.1038/sj/bjc/66002I 3 www.bjcancer.com

(c) 2002 Cancer Research UK
\end{abstract}

Keywords: fibroblast growth factor 8; human breast cancer; lactation

The fibroblast growth factors (FGFs) form a family of at least 23 growth regulatory proteins that share $35-50 \%$ amino acid sequence identity. They induce proliferation and differentiation in a wide range of cells of epithelial, mesodermal and neuroectodermal origin (Basilico and Moscatelli 1992; Tanaka et al, 1992; Hu et al, 1998; Powers et al, 2000). FGF8 was originally isolated from the conditioned medium of an androgen dependent mouse mammary carcinoma line (SC-3) as an androgen induced growth factor (AIGF) and was later assigned as a member of the fibroblast growth factor family on the basis of structural similarity (Tanaka et al, 1992). FGF8 appears to have an important role in embryogenesis and is expressed in several areas of the developing mouse and may play a critical role in gastrulation and the development of the face, limb and central nervous system (Vogel et al, 1996; Neubuser et al, 1997; Meyers et al, 1998; Ye et al, 1998; Tucker et al, 1999; Sun et al, 1999). Little expression of FGF8 has been found in adult mouse tissues with comparatively low amounts detected only in the ovaries and testes (MacArthur et al, 1995a; Lorenzi et al, 1995).

We have been interested in assessing the role of fibroblast growth factors in the normal and malignant human breast. Previous work has shown that FGF1 and FGF2 are expressed in the normal breast, implying roles for these growth factors in maintaining the structure of the normal ducts (Gomm et al, 1991, 1997; Coope et al, 1997). In breast cancer, there is a decrease in the amount of FGF1 and FGF2 present in breast tissue (Bansal et al, 1995; Yiangou et al, 1997a). However, in the case of FGF1, there is evidence for some remaining in a more functionally available form in breast cancers (Smith et al, 1994; Coope et al, 1997). FGF7 is found in similar amount in both malignant and non-

*Correspondence: Professor RC Coombes; E-mail: c.coombes@ic.ac.uk Received 18 July 200 I; revised 22 January 2002; accepted 24 January 2002 malignant breast tissues. It is produced by stromal fibroblasts and acts via the KGF receptor (FGFR2-IIIb) on epithelial cells (Bansal et al, 1997). Other studies show no expression of FGF3 and FGF4 in human breast cancers but expression of all other FGFs in at least a small proportion of breast cancers (Penault-Llorca et $a l, 1995)$. All four of the FGFRs are expressed to some degree in breast cell lines (McLeskey et al, 1994; Johnston et al, 1995). Although amplification of the $f g f r 4$ gene has been found in $10 \%$ of breast cancers, we have previously shown that equivalent levels of FGFR-4 are present in the epithelial cells of malignant and non-malignant breast sections (Jaakkola et al, 1993; Coope et al, 1997). In the case of FGFR-1, significant changes in the isoform of FGFR-1 expressed occur on malignant transformation although the level of expression appears to stay the same (Coope et al, 1997; Yiangou et al, 1997b).

One group of splice variants of the FGFR family involves the use of alternative exons encoding the carboxyl-terminal half of the third immunoglobulin domain. This form of splice variation occurs for FGFR-1, FGFR-2 and FGFR-3 so that IIIb and IIIc forms of these receptors have very different ligand binding properties (Miki et al, 1992; Werner et al, 1992; Chellaiah et al, 1994). These two isoforms appear to be expressed in a mutually exclusive fashion, with cells of mesenchymal origin expressing IIIc variants of FGFR2 and FGFR3 whereas epithelial cells express the IIIb isoform (Pekonen et al, 1993; Savagner et al, 1994). The interaction of several splice variants of FGF8 with high affinity receptors has been investigated and FGF8b has been shown to have the widest receptor binding properties, activating FGFR2-IIIc as well as FGFR3-IIIc and FGFR4 (MacArthur et al, 1995b).

FGF8 was identified as an oncogene on the basis of overexpression of FGF8 in NIH3T3 cells leading to focus formation, growth in soft agar and tumour formation in nude mice (Kouhara et al, 1994). FGF8 was subsequently found to act as a proto-oncogene 
co-operating with Wnt 1 in mouse mammary tumorigenesis (Kapoun and Shackleford, 1997). Transgenic mice in which FGF8 was expressed under an MMTV promoter developed breast cancer over a period of months implying that FGF8 may be able to promote breast cancer in mice (Daphna-Iken et al, 1998).

Previous work has shown that FGF8 is expressed by prostate and breast cancer cell lines (Tanaka et al, 1995; Schmitt et al, 1996). Some investigators have demonstrated an involvement in malignant prostate disease since FGF8 was detected in prostatic cancers, but not in benign prostatic hypertrophy (Leung et al, 1996). Further studies indicated that FGF8 over-expression was an indicator of poor prognosis (Dorkin et al, 1999). However, other groups have failed to find this correlation between tumour grade and level of FGF8 expression (Tanaka et al, 1998; Wang et al, 1999). We have previously studied the expression of FGF8 mRNA in a series of malignant and non-malignant breast tissue and found that FGF8 transcripts are more frequently detected in malignant tumours and at a higher level than benign tissue (Marsh et al, 1999). In this study, we have extended our investigations into the role of FGF8 in the human breast by using antibodies against FGF8 to detect its presence in human breast samples. We find low levels of FGF8 in normal breast epithelial cells and the level of staining appears to be increased in some breast cancers. However, the highest levels of FGF8 expression were found in lactating mammary glands, indicating a possible role for this growth factor in lactation.

We have also investigated the expression of FGF8 in normal human tissues using immunohistochemistry in order to clarify whether FGF8 also acts as a normal regulator of cell activity. Our findings indicate that FGF8 is widely expressed in the normal adult and is likely to be important in the regulation of mature tissues as well as in their development.

\section{MATERIALS AND METHODS}

\section{Tissues}

Paraffin blocks of 124 human breast tissues were used in this study. The details of the 85 breast cancer patients are shown in Table 1. Eight cases of invasive ductal carcinoma occurred in lactating tissue. The remaining tissues were from five cases of fibroadenoma, 17 normal tissues from reduction mammoplasty tissue, 11 normal lactational tissues and six cases of DCIS. Of the 85 carcinoma tissues, 54 contained elements of adjacent normal tissue.

Table I Clinical details of breast cancer patients in this study

\begin{tabular}{llc}
\hline Characteristic & & No. of patients \\
\hline Totals & & 85 \\
Age range (years) & & $32-81$ \\
Median age & Pre/peri & 57 \\
Menopausal status & Post & 31 \\
& Unknown & 50 \\
Nodal status & Positive & 4 \\
& Negative & 21 \\
& Unknown & 18 \\
Histological type & Invasive ductal & 46 \\
& Invasive lobular & 75 \\
Histological grading & Grade I & 10 \\
& Grade II & 5 \\
& Grade III & 35 \\
Oestrogen receptor & Unknown & 40 \\
& Positive & 5 \\
Progesterone receptor & Negative & 49 \\
& Unknown & 20 \\
& Positive & 16 \\
& Negative & 38 \\
& Unknown & 31 \\
& & 16 \\
\hline
\end{tabular}

Paraffin sections of normal human tissues were also analysed and included skin, rectum, duodenum, ovary, cervix, endometrium and fallopian tube.

\section{Materials}

Human milk was obtained from the milk bank at the post-natal department of Queen Charlotte's Hospital/London. FGF8 protein and antiFGF8 monoclonal antibody were obtained from R\&D systems (Abingdon, UK). All other chemicals were from Sigma (Poole, UK).

\section{Immunohistochemistry using a monoclonal antibody against FGF8}

Paraffin sections were dewaxed in xylene and hydrated through graded alcohol and heated under pressure in $0.01 \mathrm{M}$ citrate buffer pH 6.0 to reveal the antigen. Endogenous avidin and biotin were blocked using the avidin/biotin blocking kit (Vector). Non-specific binding was blocked with $10 \%$ horse serum and 5\% BSA in PBS for $30 \mathrm{~min}$. The sections were then treated for $16 \mathrm{~h}$ at $4{ }^{\circ} \mathrm{C}$ with $1 \mu \mathrm{g} \mathrm{ml}^{-1}$ anti-FGF8 monoclonal antibody (R\&D) in PBS. Control sections were incubated with $1 \mu \mathrm{g} \mathrm{ml}^{-1}$ non-immune mouse IgG (Sigma). Samples were washed three times in PBS and incubated with biotinylated anti-mouse IgG diluted in PBS with 10\% human serum for $30 \mathrm{~min}$ at room temperature. After washing three times in PBS, the sections were incubated in $\mathrm{ABC}$ reagent (Vector Laboratories) for $1 \mathrm{~h}$ at room temperature. After washing three times in PBS, staining was visualised by addition of a $0.05 \%$ solution of 3,3'-diaminobenzidine (DAB) in PBS containing $001 \%$ hydrogen peroxide. Sections were then counterstained with Gill's haematoxylin, dehydrated, cleared and mounted.

Blocking experiments were performed by incubating the antiFGF8 monoclonal antibody at $1 \mu \mathrm{g} \mathrm{ml}^{-1}$ with $100 \mu \mathrm{g} \mathrm{ml}^{-1}$ of recombinant FGF8 (R\&D) for $16 \mathrm{~h}$ at $4^{\circ} \mathrm{C}$. The antibody was then used to stain sections using the protocol described above.

\section{Scoring of staining}

The level of staining was recorded as $0,+,++$ or +++ with 0 indicating no staining and +++ maximal staining. Scoring was checked by a histopathologist, experienced in breast disease who was blinded to the preliminary scoring results. Comparison of staining levels in oestrogen receptor positive and negative tumours or progesterone receptor positive and negative tumours was done using the Mann Whitney $U$-test. These receptor analysis were done routinely with primary tissue analysis at time of surgery by the histopathology laboratory at Charing Cross Hospital, London, using conventional techniques.

\section{Western blot detection of FGF8}

Samples containing recombinant FGF or protein precipitated from milk were run on a $12 \%$ polyacrylamide gel and then transferred onto nitrocellulose for $16 \mathrm{~h}$ at $200 \mathrm{~mA}$. The nitrocellulose was blocked by incubating with $3 \%$ casein in PBS with $0.1 \%$ Tween 20 for $1 \mathrm{~h}$. The blot was probed with monoclonal anti-FGF8 (R\&D) for $1 \mathrm{~h}$ and was washed three times in PBS. Incubation with an anti-mouse IgG-horseradish peroxidase conjugate (Sigma) was followed by extensive washes in PBS with $0.1 \%$ washes in PBS with $0.1 \%$ Tween 20 and development with ECL reagents (Amersham). Milk protein samples were prepared by centrifuging milk at $1000 \mathrm{~g}$ for $10 \mathrm{~min}$ to separate fat from milk. The semi-skimmed milk was filtered through a Microcon 100 to eliminate proteins of a molecular weight higher than $100 \mathrm{kDa}$. The milk solution was acidified to $\mathrm{pH} 4.6$ using $1 \mathrm{M} \mathrm{HCl}$ to precipitate casein. This was centrifuged at $400 \mathrm{~g}$ for $30 \mathrm{~min}$ and the supernatant collected and neutralised to $\mathrm{pH} 7.6$ with $\mathrm{NaOH}$. The resulting proteins were used in Western analysis. 


\section{RESULTS}

\section{Specificity of the monoclonal antibody against FGF8}

The specificity of the antibody to be used in immunohistochemistry was tested for its cross-reactivity against members of the FGF family by Western blotting. Equal amounts of recombinant FGF1, FGF2, FGF7, FGF8 and FGF9 were run on a $12 \%$ polyacrylamide gel. After transfer to nitrocellulose, the blot was probed using the monoclonal antibody against FGF8. No cross-reactivity with FGF 1, 2, 7 or 9 was seen (Figure 1).

\section{Expression of FGF8 in human breast tissues}

We have previously reported that FGF8 mRNA is expressed at a higher level in breast cancer cells than in normal breast epithelial cells (Marsh et al, 1999). Following these observations, we have used a monoclonal antibody against FGF8 in immunohistochemistry to assess the expression and distribution of FGF8 in a series of malignant and non-malignant human breast tissues. Details of the breast cancer patients studied are shown in Table 1 and in addition, 17 normal reduction mammoplasty tissues, five cases of fibroadenoma and 11 normal lactating breast tissues were analysed.

Immunostaining of human breast sections from invasive ductal carcinoma (Figure 2A,B), invasive lobular carcinoma (Figure 2C,D) and DCIS (Figure 2E,F) showed expression of FGF8 in epithelial cells but not of adjacent stromal elements (Figure 2A,C,E). FGF8 was not found in the nuclei of cells and gave a diffuse cytoplasmic staining pattern. The staining appeared to be specific since pre-incubation of anti-FGF8 with excess recombinant FGF8, blocked the staining (Figure 2D) and non-immune mouse IgG at the same concentration gave negative staining (Figure 2B,F).

FGF8 immunostaining could also be detected in non-malignant breast tissues. In cases of reduction mammoplasty tissue, cytoplasmic FGF8 staining was seen in epithelial cells but not in myoepithelial cells or in stromal elements (Figure 3A). Fibroadenoma tissues also showed cytoplasmic FGF8 immunostaining in the epithelial cells (Figure 3C). In sections where normal elements of breast tissues could be seen adjacent to invasive carcinoma, higher levels of FGF8 staining were consistently seen in carcinoma elements compared to normal elements (Figure 3E,F). The intensity of FGF8 immuno-reactivity was graded as $0,+,++$ or +++ and a score was given to the tissues analysed.

A comparison of the level of FGF8 immuno-reactivity in fibroadenoma, normal breast tissue from reduction mammoplasty and

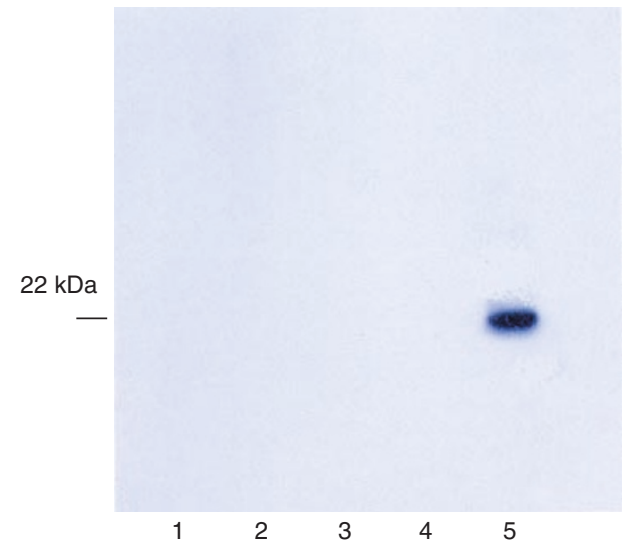

Figure I Western blots showing the specificity of the anti-FGF8 antibody. One hundred ng of FGFI (lane I), FGF2 (lane 2), FGF7 (lane 3), FGF9 (lane 4) and FGF8 (lane 5) were run on a 15\% polyacrylamide gel and transferred onto nitrocellulose filters. These were probed with antiFGF8 monoclonal antibody. lactational breast tissue (Figure 4A); DCIS, lobular breast cancer tissue and different grades of invasive ductal carcinoma is shown (Figure 4B). In general, we found an increase in FGF8 expression in malignant breast tissues compared to non-malignant. Hence comparatively low levels of FGF immunoreactivity were found in normal breast tissue from reduction mammoplasty tissue with the majority of tissues registering as + and ++ . Fibroadenoma tissues also showed similar low levels of FGF8 expression as normal breast tissue. DCIS, lobular carcinoma and ductal carcinoma tissues more commonly registered as ++ and +++ . We observed no significant difference in FGF8 expression between invasive lobular and invasive ductal carcinoma. No significant difference in the level of FGF8 immunoreactivity was seen in invasive ductal carcinomas of histological grades II and III. The Grade I breast carcinoma specimens showed similar low expression of FGF8 as normal breast tissues but statistical comparative analysis with higher tumour grades was not possible as numbers were small. No significant difference in FGF8 expression was seen in cancers with different oestrogen receptor status $(P=0.5)$, progesterone receptor status $(P=0.0534)$ or nodal status $(P=0.138)$.
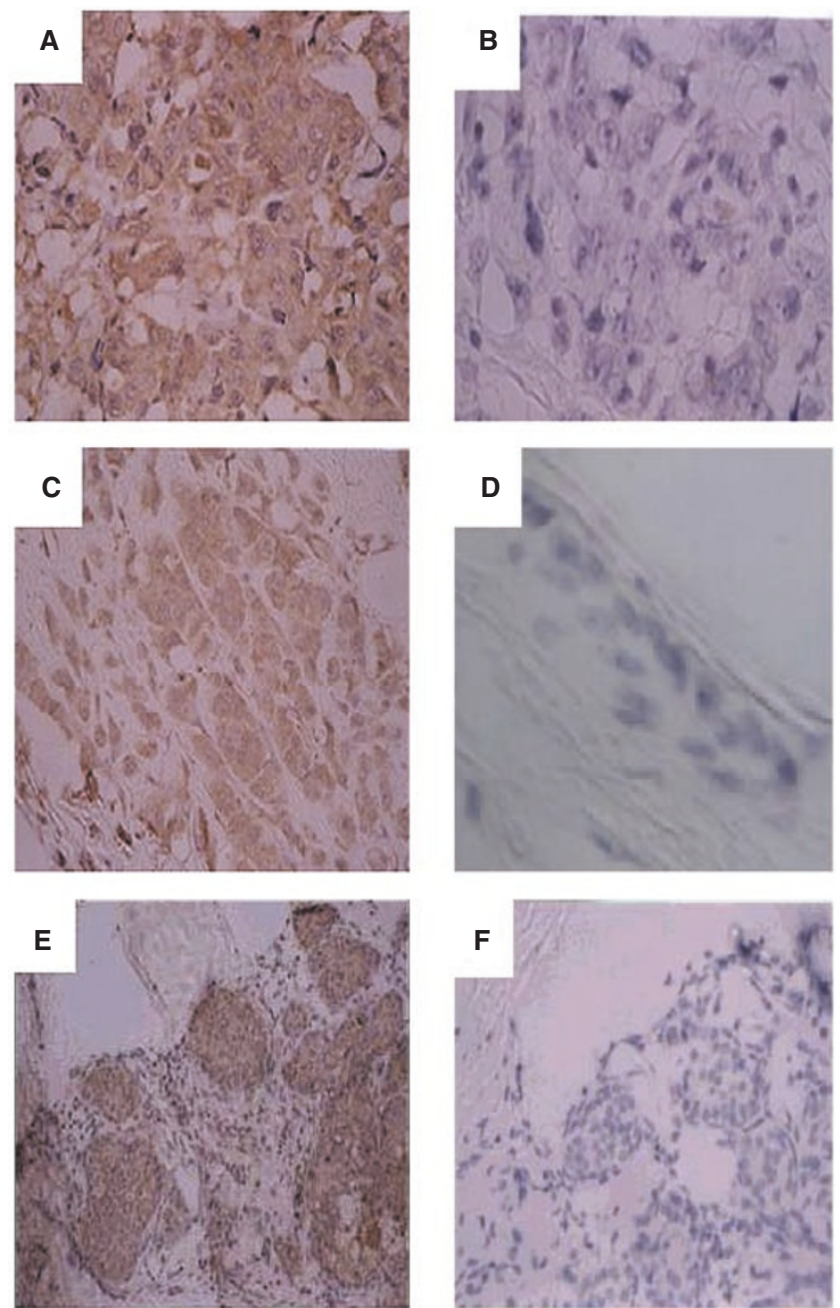

Figure 2 Expression of FGF8 in human breast cancer tissue. Paraffin sections of invasive ductal carcinoma $(\mathbf{A}, \mathbf{B})$, invasive lobular carcinoma $(\mathbf{C}, \mathbf{D})$ and ductal carcinoma in situ (DCIS) (E,F), were analysed by immunohistochemistry using an antibody against FGF-8 (A,C,E) or the equivalent concentration of non-immune mouse $\operatorname{lgG}(\mathbf{B}, \mathbf{F})$. (D) Shows absence of antiFGF8 staining after pre-incubation with 100 -fold excess of recombinant FGF8. (Original magnification A-D, $\times 400 ; \mathbf{E}, \mathbf{F}, \times 200$ ). 

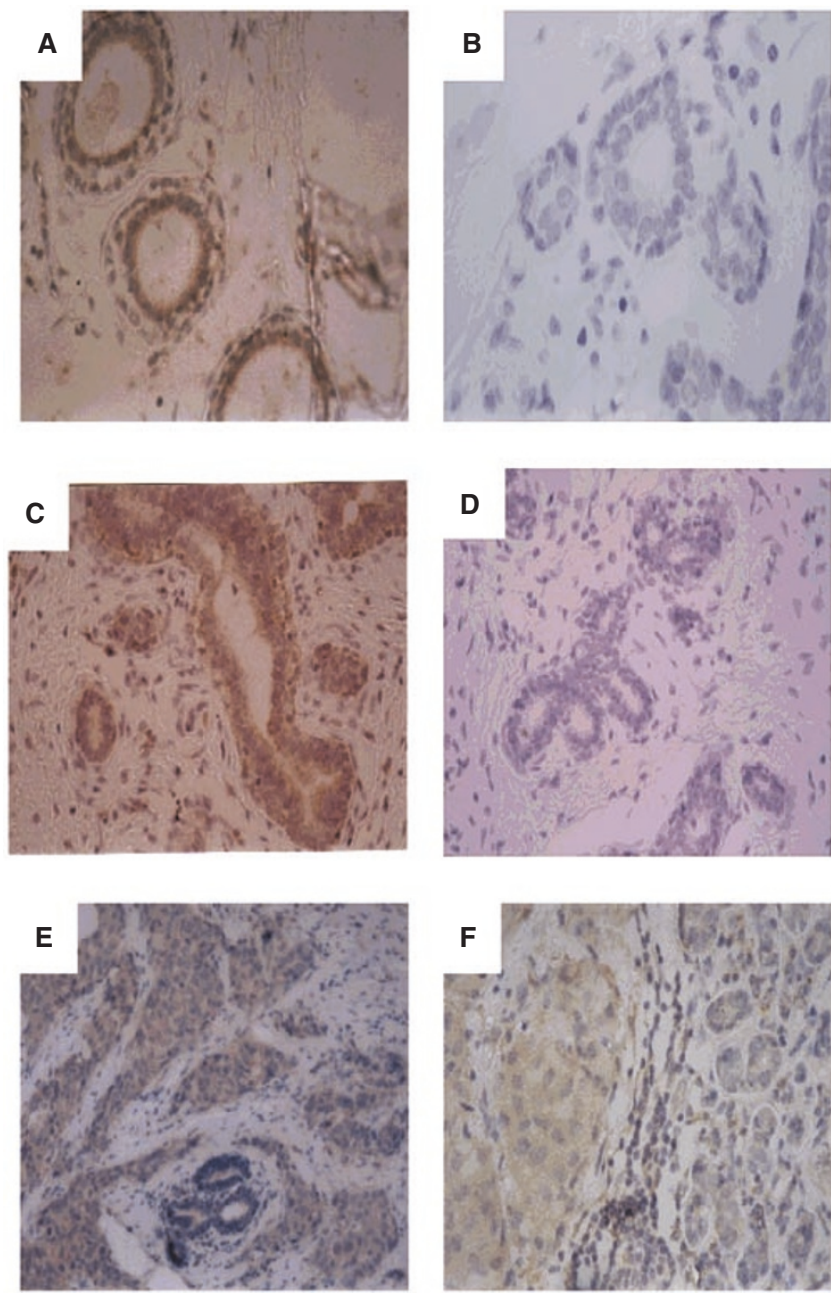

Figure 3 Expression of FGF8 in non-malignant human breast tissue. Paraffin sections of normal breast tissue from reduction mammoplasty tissue $(\mathbf{A}, \mathbf{B})$, fibroadenoma $(\mathbf{C}, \mathbf{D})$ and paraffin sections containing elements of both invasive ductal carcinoma and adjacent normal breast tissues (E,F), were analysed by immunohistochemistry using an antibody against FGF8 $(\mathbf{A}, \mathbf{C}, \mathbf{E}, \mathbf{F})$ or the equivalent concentration of non-immune mouse $\mathrm{IgG}$ $(\mathbf{B}, \mathbf{D})$. (Original magnification $\mathbf{A}-\mathbf{B}, \times 400 ; \mathbf{C}-\mathbf{F} \times 200$ ).

\section{FGF8 expression in lactating breast}

A series of sections from lactating breasts were stained for FGF8 and all showed levels of FGF8 expression higher than any of the normal or malignant breast sections. Again cytoplasmic staining of epithelial cells was seen with myoepithelial cells and stromal components being negative (Figure 5). Protein was isolated from samples of human milk and Western blot analysis was used to assess whether FGF8 was present. Five samples of milk analysed all contained FGF8 (Figure 6).

\section{FGF8 expression in other tissues}

Previous reports concerning FGF8 expression in adult mouse tissues showed only a small amount of FGF8 expression in ovaries and testes (Lorenzi et al, 1995). To see whether this is a true reflection of FGF8 expression in normal human tissues, an immunohistochemical study was carried out. FGF8 immunoreactivity was present within the epidermal layer of the skin (Figure $7 \mathrm{G}, \mathrm{I})$. The greatest levels of FGF8 staining was found towards the bottom of the epidermal layer containing dividing cells rather than in the more differentiated upper layers. Sections of skin

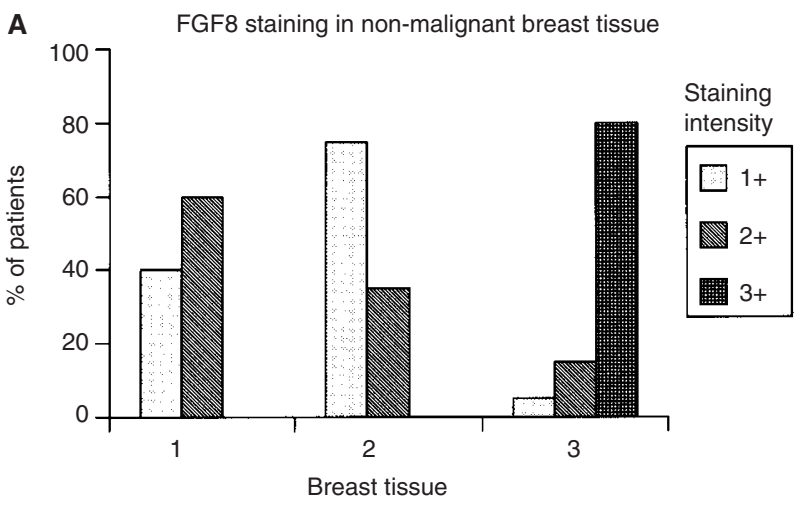

(1=Fibroadenoma, 2=Normal breast, 3=Lactational breast)

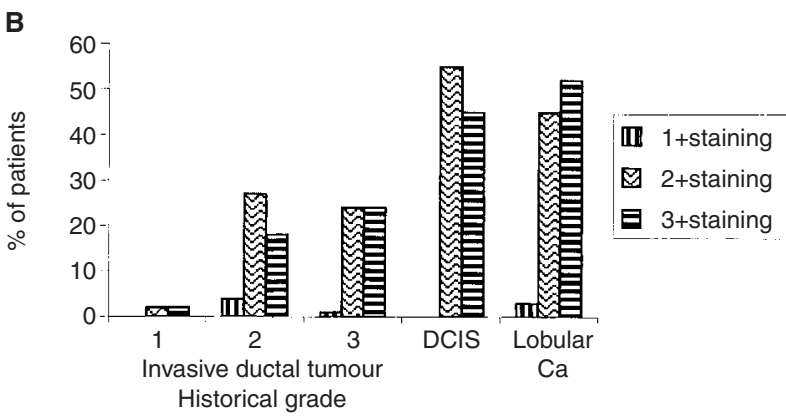

Figure 4 Histograms showing the level of FGF8 immunoreactivity in malignant and non-malignant breast tissue. Tissues were scored as,+++ or +++ for FGF8 staining. (A) Shows percentages of patients with each level of staining in: I=Fibroadenoma; 2=Normal breast tissue (reducton mammoplasty); 3=Lactating breast tissue. (B) Shows FGF8 staining patterns in Invasive Ductal Carcinoma Grade I, 2 and 3; DCIS and Lobular carcinoma.
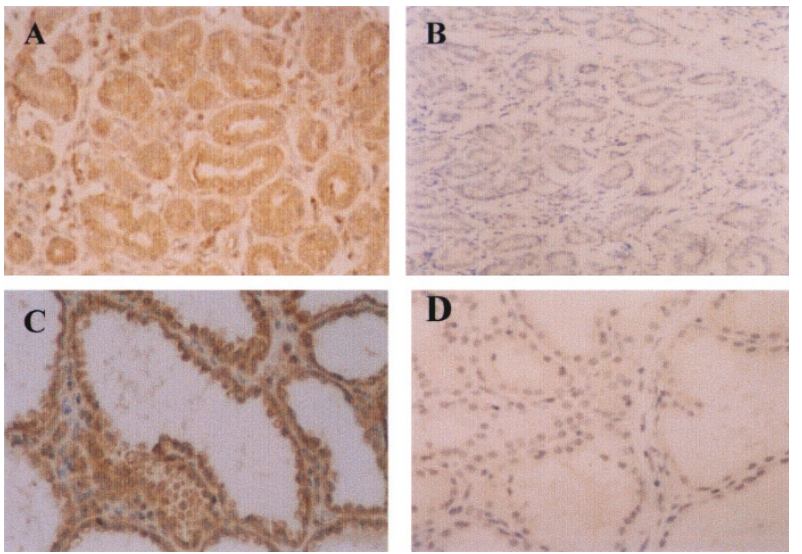

Figure 5 FGF8 staining in lactating mammary gland. Paraffin sections of lactating mammary gland tissue were stained with an antibody against FGF8 (A,C) or with the equivalent concentration of non-immune mouse $\operatorname{lgG}(\mathbf{B}, \mathbf{D})$. (Original magnification A, B, $\times 200 ; \mathbf{C}, \mathbf{D}, \times 400$ ).

containing sweat glands showed high FGF8 staining of the sweat glands (Figure 7I).

FGF8 expression was also detected within the human bowel. Sections of rectum showed immunoreactivity at the base of goblet cells and in surface epithelial cells (Figure 7J,K). Interstitial lymphocytes and plasma cells were stained positive. In sections of duodenum, columnar absorptive cells showed positive cytoplasmic staining mainly at the base but also in more superficial parts of some cells (Figure 7E). Intestinal Goblet cells and 
Paneth cells showed less positive staining, mainly at the base of the cells.

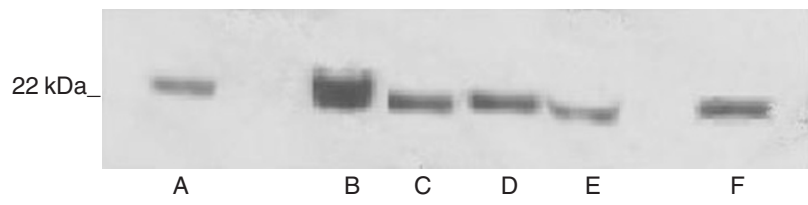

Figure 6 Western blots demonstrating the presence of FGF8 in human breast milk. Proteins from human milk samples were run on a $12 \%$ polyacrylamide gel, transferred onto nitrocellulose and probed using the monoclonal antibody against FGF8. Lanes $\mathbf{A}-\mathbf{E}$ contain milk proteins and lane $F$ contains $100 \mathrm{ng}$ of recombinant FGF8.
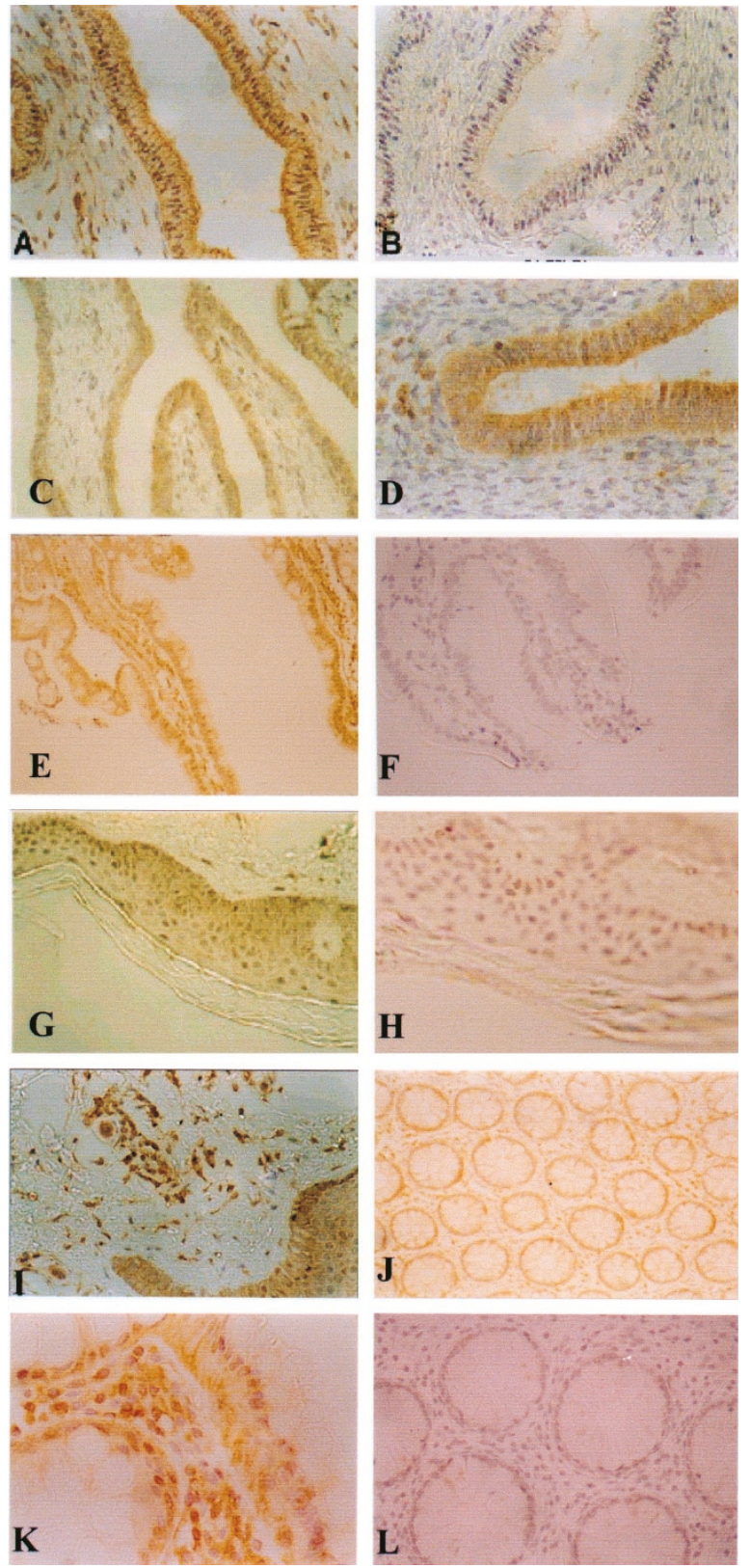

Figure 7 Immunostaining of different normal human tissues. Shown are section of endometrium $(\mathbf{A}, \mathbf{B})$; fallopian tube $(\mathbf{C})$; endocervix $(\mathbf{D})$; duodenum (E,F); skin (G,H); skin with sweat glands (I); rectum (J,K and $\mathbf{L})$. (Original magnification $\mathbf{A}-\mathbf{H}, \mathbf{J}, \mathbf{L}, \times 200 ; \mathbf{I}, \mathbf{K}, \times 200$.
In the ecto-cervix, the stratified squamous layer showed faint staining but the keratin layer was clear. More immunoreactivity was found in the endocervix with columnar cells lining glands showing positive staining (Figure 7D). FGF8 expression was also seen in the columnar epithelial cells of the fallopian tube (Figure 7C). Within the ovary, high levels of FGF8 were seen in the Corpus Luteum. In the endometrium, glands showed positive staining (Figure 7A). The endometrial stroma was negative, however the myometrium showed positive staining.

\section{DISCUSSION}

FGF8 is of potential interest in breast biology since it was first isolated from a mouse mammary carcinoma cell line and its expression is regulated by steroid hormones; in particular dihydroxytestosterone (Tanaka et al, 1992; Payson et al, 1996). FGF8 is able to function as an oncogene, causing transformation of NIH3T3 cells and inducing breast tumours in transgenic mice expressing FGF8 under an MMTV promoter (Kouhara et al, 1994; Daphna-Iken et al, 1998). FGF8 expression appears to be associated with human carcinoma of the prostate since higher levels of FGF8 were detected in malignant prostate disease (Leung et al, 1996; Tanaka et al, 1998). However, another group found FGF8 expressed in benign prostatic hypertrophy as well as prostate cancer (Wang et al, 1999). FGF8 expression has also been shown in a proportion of breast cancers and normal breast tissues (Tanaka $e t$ al, 1998; Marsh et al, 1999). Although immunohistochemical studies have been carried out showing a correlation between the grade of prostate cancers and the amount of FGF8 expression, such extensive studies have not previously been carried out using human breast tissue. Our studies show that although FGF8 expression appears to be slightly higher in malignant breast disease than in normal breast tissue, FGF8 is expressed in normal epithelial cells and in fact the highest level of FGF8 expression were found in lactating mammary gland.

The results of the staining are consistent with previously published reports. mRNA encoding FGF8 mRNA has been found expressed in the epithelial cells of breast cancer using in situ hybridisation and we find a similar expression pattern in the epithelial component of normal and malignant breast tissue (Marsh et al, 1999). It has been reported that FGF8 mRNA is present in a proportion of both malignant and non-malignant breast tissues (Wu et al, 1997; Tanaka et al, 1998). Our findings show that the majority of breast epithelial cells contain considerable levels of FGF8 protein.

The staining pattern observed indicates that FGF8 has a cytoplasmic or membrane bound localisation but is not seen in the nucleus of epithelial cells. This is in contrast with several other members of the FGF family. FGF 1, 2 and 3 have been detected in the cell nucleus (Cao et al, 1993; Presta et al, 1993; Antoine et $a l$, 1997). Eight different splice variants of FGF8 are possible in the mouse but in man due to a stop codon only four of these forms are possible (Crossley and Martin, 1995; Gemel et al, 1996). Previous studies have indicated that FGF8b is the predominant form in breast tissue (Marsh et al, 1999) and that FGF8b has been shown to have the greatest transforming ability (MacArthur et $a l$, 1995b). The monoclonal anti-FGF8 antibody used in this study (R\&D Systems) was produced from a mouse hybridoma in which the immunogen was an E. coli-derived recombinant mouse fibroblast growth factor $8 \mathrm{~b}$.

Transgenic mice overexpressing FGF8 under an MMTV promoter have been reported to produce lobular carcinoma of the breast (Daphna-Iken et al, 1998). We therefore compared the levels of FGF8 staining in groups of invasive ductal and invasive lobular carcinoma. We failed to detect any difference in FGF8 expression in the two groups, suggesting that the causal relationship implied in mice may not be important in humans. A comparison of FGF8 expression in different histological grades of ductal carcino- 
ma also showed no difference between staining in different grades of breast tumour. This is in contrast to a prostate cancer report in which higher levels of FGF8 were found in less differentiated cancers (Leung et al, 1996; Tanaka et al, 1998; Dorkin et al, 1999). It is known that FGF8 expression is regulated by androgens (Tanaka et al, 1992). We see no evidence of higher FGF8 expression correlating with loss of oestrogen or progesterone receptors. Previous reports have shown that dihydoxytestesterone but neither oestrogen nor progesterone was able to upregulate FGF8 expression (Payson et al, 1996). In view of these findings, it is not surprising that FGF8 expression fails to correlate with ER or PR status.

The highest levels of FGF8 expression were detected in lactating mammary gland, strongly implicating FGF8 as having an important role in lactation. A large number of hormones and related peptides are present in milk and colostrum; insulin, epidermal growth factor (EGF), insulin-like growth factor I (IGF-I) and cortisol are abundantly present $(\mathrm{Xu}, 1996)$. FGF8 has been implicated in embryological development especially gastrulation suggesting roles in brain, limb and facial development (Ohuchi et al, 2000). FGF8 has also been implicated in morphogenic outgrowth of the hepatic endoderm (Jung et al, 1999). However in the early post natal period the gastrointestinal tract is still in a process of development and maturation which seem to be under the influence of milk ingested (Xu, 1996). With the presence of high quantities of FGF8 in human milk, FGF8 along with other growth/hormonal factors may be implicated in this process.

We also used immunohistochemistry to determine the expression of FGF8 in normal adult tissues. By this method, we were able to detect FGF8 expression in the epithelial cells of many of the tissues examined. The widespread expression pattern suggests that FGF8 has physiological roles in adult tissue as well as in development.

Previous studies have used Northern blotting and in situ hybridisation to detect FGF8 expression. High levels of FGF8 mRNA were found during development in the mouse whereas in the adult mouse a little expression was found in ovary and testis (Lorenzi et al, 1995). Our results confirm expression of FGF8 in the ovary, however more widespread expression was apparent. This could indicate that the immunohistochemical method used is more sensitive or it could reflect a difference between the two species. Our finding of FGF8 expression in normal breast tissue is in agreement with previous reports studying mRNA and protein levels (Tanaka et al, 1998; Marsh et al, 1999). Since we have not included foetal tissue in this study, it is possible that higher levels are present in development.

Other members of the FGF family are expressed in adult tissues and in many cases the activity of such growth factors is tightly regulated to prevent inappropriate cell responses. In the case of FGF1 and FGF2, release is the point of regulation since these growth factors lack a signal peptide and are therefore not secreted by the classical pathway. Release of these growth factors is possible but appears to be regulated by binding of integrins to extracellular

\section{REFERENCES}

Antoine M, Reimers K, Dickson C, Kiefer P (1997) Fibroblast growth factor 3 a protein with dual subcellular localization, is targeted to the nucleus and nucleolus by the concerted action of two nuclear localization signals and a nucleolar retention signal. J Biol Chem 272: 29475-29481

Bansal GS, Yiangou C, Coope RC, Gomm JJ, Luqmani YA, Coombes RC, Johnston CL (1995) Expression of fibroblast growth factor 1 is lower in breast cancer than in the normal human breast. $\mathrm{Br} J$ Cancer 72: $1420-1426$

Bansal GS, Cox HC, Marsh S, Gomm JJ, Yiangou C, Coombes RC, Johnston CL (1997) Expression of keratinocyte growth factor and its receptor in human breast cancer. Br J Cancer 75: $1567-1574$

Basilico C, Moscatelli D (1992) The FGF family of growth factors and oncogenes. Adv Cancer Res 59: 115-165

Cao Y, Ekstrom M, Pettersson RF (1993) Characterization of the nuclear translocation of acidic fibroblast growth factor. J Cell Sci 104: 77-87 matrix components and other factors such as oestrogen stimulation (Mousa et al, 1999).

Since FGF8 contains a signal peptide, its regulation is more likely to follow the model of FGF7. FGF7 binds to only one FGF receptors, the IIIb isoform of FGFR-2. Since ephithelial cells exclusively express FGFR2-IIIb and FGF7 is secreted by fibroblasts, FGF7 is likely to act in a paracrine fashion (Bansal et al, 1997). A similar situation may occur in the case of FGF8, which is expressed principally in epithelial cells with very little expression seen in stromal tissues in this study and in other reports (Tanaka et al, 1998; Marsh et al, 1999). Its receptor binding properties have been reported previously and the highest affinity receptors are FGFR2IIIc, FGFR3-IIIc and FGFR4 (Ornitz et al, 1996). Both FGFR2-IIIC and FGFR3-IIIc receptors are expressed predominantly in fibroblasts (Yan et al, 1993; Scotet and Houssaint, 1995). Again this raises the likelihood of FGF8 operating through a paracrine interaction, being released by epithelial cells and acting on surrounding fibroblasts. FGFR4 is another receptor for FGF8.We have previously shown that FGFR4 is present in epithelial cells of normal (including lactating breast) and malignant breast tissue (Coope et al, 1997), therefore an autocrine loop of FGF8/FGFR4 is also possible.

Detailed immunohistochemical staining for FGFRs has been carried out on a range of normal human tissues and show widespread expression of this family of proteins in the normal adult (Hughes, 1997). Within the skin, high levels of FGFR2 were found in dermal fibroblasts. FGF8 expression is found in the basal level of the skin, providing a potential paracrine interaction for FGF8. A high level of FGFR3 expression was found in the cervix including its presence in stromal fibroblasts. The presence of FGF8 in the epithelial cells of the cervix suggests a similar paracrine interaction with the stroma. In the duodenum, expression of FGFR2 and FGFR3 was found in the muscularis mucosae giving potential interactions for the FGF8 released by columnar epithelial cells. High level of FGFR-3 were also detected in the colon. No expression of FGFR-2 or FGFR-3 was found in the ovary.

The widespread expression of FGF8 in normal tissues implicates this growth factor as having a physiological role in the adult as well as during development. Because of its production by epithelial cells and the presence of its receptors on fibroblasts, it probably has a paracrine mode of action in skin, cervix, duodenum and rectum. Its function in the endometrium and ovary is less clear since FGF8 appears to be localised towards the apical surface of epithelial cells in these tissues.

\section{ACKNOWLEDGEMENTS}

This work was supported by grants from Cancer Research UK and the Buckle Family Trust.
Chellaiah AT, McEwan DG, Werner S, Xu J, Ornitz DM (1994) Fibroblast growth factor receptor (FGFR) 3. Alternative splicing in immunoglobulin-like domain III creates a receptor highly specific for acidic FGF/FGF1. J Biol Chem 269: $11620-11627$

Coope R, Browne PJ, Yiangou C, Bansal GS, Walters J, Groome N, Shousha S, Johnston CL, Coombes RC, Gomm JJ (1997) The location of acidic fibroblast growth factor in the breast is dependent on the activity of proteases present in the breast. $\mathrm{Br} J$ Cancer 75: $1621-1630$

Crossley PH, Martin GR (1995) The mouse fgf 8 gene encodes a family of polypeptides and is expressed in regions that direct outgrowth and patterning in the developing embryo. Development 121: 439-451

Daphna-Iken D, Shankar DB, Lawshe A, Ornitz DM, Shackleford GM, MacArthur CA (1998) MMTV-fgf8 transgenic mice develop mammary and salivary gland neoplasia and ovarian stromal hypoplasia. Oncogene 17: $2711-2717$ 
Dorkin TJ, Robinson MC, Marsh C, Bjartell A, Neal DE, Leung HY (1999) FGF8 over-expression in prostate cancer is associated with decreased patient survival and persists in androgen independent disease. Oncogene 18: $2755-2761$

Gemel J, Gorry M, Ehrlich GD, MacArthur CA (1996) Structure and sequence of human FGF8. Genomics 35: 253-257

Gomm J, Smith J, Ryall GK, Baillie R, Turnbull L, Coombes RC (1991) Localisation of basic fibroblast growth factor and transforming growth factor beta 1 in the human mammary gland. Cancer Res 51: 4685-4692

Gomm JJ, Browne PJ, Coope RC, Bansal GS, Yiangou C, Johnston CL, Mason R, Coombes RC (1997) A paracrine role for myoepithelial cell-derived FGF2 in the normal human breast. Exp Cell Res 234: 165-173

Hu MC, Qiu WR, Wang Y, Hill D, Ring BD, Scully S, Bolon B, DeRose M, Luethy R, Simonet WS, Arakawa T, Danilenko DM (1998) FGF18, a novel member of the fibroblast growth factor family stimulates hepatic and intestinal proliferation. Mol Cell Biol 18: 6063-6074

Hughes SE (1997) Differential expression of the fibroblast growth factor receptor (FGFR) multigene family in normal human adult tissues. J Histochem Cytochem 45: 1005-1019

Jaakkola S, Salmikangas P, Nylund S, Partanen J, Armstrong E, Pyrhonen S, Lehtovirta P, Nevanlinna H (1993) Amplification of FGFR-4 gene in human breast and gynaecological cancers. Int J Cancer 54: 378-382

Johnston CL, Cox H, Gomm JJ, Coombes RC (1995) Fibroblast growth factor receptors (FGFRs) localize in different cellular compartments. J Biol Chem 270: $30643-30650$

Jung J, Zheng M, Goldfarb M, Zaret KS (1999) Initiation of mammalian liver development from endoderm by fibroblast growth factors. Science 284: $1998-2003$

Kapoun AM, Shackleford GM (1997) Preferential activation of fgf8 by proviral insertion in mammary tumours of Wntl transgenic mice. Oncogene 14: $2985-2989$

Kouhara H, Koga M, Kasayama S, Tanaka A, Kishimoto T, Sato B (1994) Transforming activity of a newly cloned androgen-induced growth factor. Oncogene 9: 455-462

Leung HY, Dickson, C, Robson CN, Neal DE (1996) Over-expression of fibroblast growth factor 8 in human prostate cancer. Oncogene 12: $1833-1835$

Lorenzi MV, Long JE, Miki T, Aaronson SA (1995) Expression cloning, developmental expression and chromosomal localisation of fibroblast growth factor 8. Oncogene 10: 2051-2055

MacArthur CA, Shankar DB, Shackleford GM (1995a) Fgf-8 activation by proviral insertion, co-operates with the Wnt-1 transgene in murine mammary carcinogenesis. J Virol 69: 2501-2507

MacArthur CA, Lawshe A, Shankar DB, Heikineimo M, Shackleford GM (1995b) FGF-8 isoforms differ in NIH3T3 cell transforming potential. Cell Growth Diff 6: $817-825$

Marsh SK, Bansal GS, Zammit C, Coope R, Roberts-Clarke D, Barnard R, Gomm JJ, Coomes RC, Johnston CL (1999) Increased expression of fibroblast growth factor 8 in human breast cancer. Oncogene 18: 1053- 1060

McLeskey SW, Ding IYF, Lippman ME, Kern FG (1994) MDA-MB-134 breast carcinoma cells overexpress fibroblast growth factor receptors and are growth inhibited by FGF ligands. Cancer Res 54: 523-530

Miki T, Bottaro D, Fleming T, Smith C, Burgess W, Chan A, Aaronson S (1992) Determination of the ligand-binding specificity by alternative splicing. Two distinct growth factor receptors encoded by a single gene. Proc Natl Acad Sci USA 89: 246-250

Meyers EN, Lewandoski M, Martin GR (1998) An FGF8 mutant allelic series generated by Cre- and Flp- mediated recombination. Nat Genet 18: $136-$ 141

Mousa SA, Lorelli W, Campochiaro PA (1999) Role of hypoxia and extracellular matrix-integrin binding in the modulation of angiogenic growth factors secretion by retinal pigmented epithelial cells. $J$ Cell Biochem 74: $135-143$

Neubuser A, Peters H, Balling R, Martin GR (1997) Antagonistic interactions between FGF and BMP signaling pathways: a mechanism for positioning the sites of tooth formation. Cell 90: 247-255

Ohuchi H, Kimura S, Watamoto M, Itoh N (2000) Involvement of fibroblast growth factor (FGF) 18-FGF8 signaling in specification of left-right asymmetry brain limb development of the chick embryo. Mech Dev 95: 55-66

Ornitz DM, Xu J, Colvin JS, McEwen DG, MacArthur CA, Coulier F, Gao G, Goldfarb M (1996) Receptor specificity of the fibroblast growth factor family. J Biol Chem 271: $15292-15297$

Payson RA, Wu J, Liu Y, Chu I (1996) The human FGF8 gene localizes on chromosome 10q24 and is subjected to induction by androgen in breast cancer cells. Oncogene 13: 47-53
Pekonen F, Nyman T, Rutanen EM (1993) Differential expression of keratinocyte growth factor and its receptor in the human uterus. Mol Cell Endocrinol 95: 43-49

Penault-Llorca F, Bertucci F, Adelaide J, Parc P, Coulier F, Gao G, Goldfarb M (1995) Expression of FGF and FGF receptors in human breast cancer. Int J Cancer 61: 170 - 176

Powers CJ, McLeskey SW, Wellstein A (2000) Fibroblast growth factors, their receptors and signaling. Endocr Relat Cancer 7: 165-197

Presta M, Gualandris A, Urbinati C, Rusnati M, Coltrini D, Isacchi A, Caccia P, Bergonzoni L (1993) Subcellular localization and biological activity of $\mathrm{M}(\mathrm{r})$ 18,000 basic fibroblast growth factor: site-directed mutagenesis of a putative nuclear translocation sequence. Growth Factors 9: 269-278

Savagner P, Valles AM, Jouanneau J, Yamada KM, Thiery JP (1994) Alternative splicing in fibroblast growth factor receptor 2 is associated with induced epithelial-mesenchymal transition in rat bladder carcinoma cells. Mol Cell Biol 5: 851-862

Schmitt JF, Hearn MTW, Risbridger GP (1996) Expression of fibroblast growth factor 8 in adult rat tissues and human prostate carcinoma cells. J Steroid Biochem Mol Biol 57: 173 - 178

Scotet E, Houssaint E (1995) The choice between alternative IIIb and IIIc exons of the FGFR-3 gene is not strictly tissue-specific. Biochimica et Biophysica Acta 264: $238-242$

Smith J, Yelland A, Baillie R, Coombes RC (1994) Acidic and basic fibroblast growth factors in human breast tissue. Eur J Cancer 30: 496-503

Sun X, Meyers EN, Lewandoski M, Martin GR (1999) Targeted disruption of fgf8 causes failure of cell migration in the gastrulating mouse embyro. Genes Dev 13: $1834-1846$

Tanaka A, Miyamoto K, Minamino N, Takeda M, Sato B (1992) Cloning and characterisation of an androgen-dependent growth factor of mammary carcinoma cells. Proc Natl Acad Sci USA 89: 8928-8932

Tanaka A, Miyamoto K, Matsuo H, Matsumoto K, Yoshida H (1995) Human androgen-induced growth factor in prostate and breast cancer cells: its molecular cloning and growth properties. FEBS Letts 363: 226-230

Tanaka A, Furuya A, Yamasaki M, Hanai N, Kuriki K, Kamiakito T, Kobayashi Y, Yoshida H, Koike M, Fukayama M (1998) High frequency of FGF8 expression in clinical prostate cancers and breast tissues, immunohistochemically demonstrated by a newly established neutralising monoclonal antibody. Cancer Res 58: 2053-2056

Tucker AS, Khamis A, Ferguson CA, Bach I, Rosenfeld MG, Sharpe PT (1999) Conserved regulation of mesenchymal gene expression by FGF-8 in face and limb development. Development 126: $221-228$

Vogel A, Rodriguez C, Izpisua-Belmonte J (1996) Involvement of FGF-8 in the initiation, outgrowth and patterning of the vertebrate limb. Development 122: $1737-1750$

Wang Q, Stamp GW, Powell S, Abel P, Laniado M, Mahony C, Lalani EN, Waxman J (1999) Correlation between androgen receptor expression and FGF8 mRNA levels in patients with prostate cancer and benign prostatic hypertrophy. J Clin Pathol 52: 29-34

Werner S, Duan DS, de Vries C, Peters KG, Johnson DE, Williams LT (1992) Differential splicing in the extracellular region of fibroblast growth factor receptor 1 generates receptor variants with different ligand-binding specificities. Mol Cell Biol 12: $82-88$

Wu J, Payson RA, Lang JC, Chiu I (1997) Activation of fibroblast growth factor 8 gene expression in human embryonal carcinoma cells. J Steroid Mol Biol 62: 1 - 10

Xu RJ (1996) Development of the newborn GI tract and its relation to colostrum/milk intake: a review. Reprod Fertil Dev 8: $35-48$

Yan G, Fukabori Y, McBride G, Nikolaropolous S, McKeehan WL (1993) Exon switching and activation of stromal and embryonic fibroblast growth factor (FGF)-FGF receptor genes in prostate epithelial cells accompany stromal independence and malignancy. Mol Cell Biol 13: 4513-4522

Ye W, Shimamura K, Rubenstain JLR, Mynes MA, Rosenthal A (1998) FGF and Shh signals control dopamineric and serotonergic cell fate in the anterior neural plate. Cell 93: 755-766

Yiangou C, Gomm JJ, Coope RC, Law M, Luqmani YA, Shousha S, Coombes RC, Johnston CL (1997a) Fibroblast growth factor 2 in breast cancer: occurrence and prognostic significance. Br J Cancer 75: 28-33

Yiangou C, Cox H, Bansal GS, Coope R, Gomm JJ, Barnard R, Walters J, Groome N, Shousha S, Coombes RC, Johnston CL (1997b) Down-regulation of a novel form of fibroblast growth factor receptor 1 in human breast. Br J Cancer 76: $1419-1427$ 